\title{
PENGARUH PENGGUNAAN LARUTAN NaOH 1\% PADA PRA-PERLAKUAN ECENG GONDOK UNTUK PRODUKSI BIOGAS
}

\author{
The Influence of $\mathrm{NaOH} 1 \%$ Solution for Water Hyacinth Pre- \\ Treatment as Biogas Production Raw Material
}

\author{
Purwinda Iriani ${ }^{1}$, Akmalurijal Asyipa ${ }^{2}$ \\ Jurusan Teknik Konversi Energi, Politeknik Negeri Bandung \\ e-mail: purwinda_iriani@yahoo.com
}

\begin{abstract}
Abstrak
Biogas merupakan salah satu bahan bakar terbarukan yang dapat diproduksi dengan berbagai bahan baku biomassa. Salah satu sumber biomassa yang ketersediaannya berlimpah yaitu eceng gondok mempunyai kandungan polisakarida berupa selulosa dan hemiselulosa cukup tinggi, sedangkan produksi biogas membutuhkan bahan baku dengan kandungan polisakarida yang rendah. Metode pemecahan ikatan polisakarida menjadi monomer-monomernya menggunakan metode hidrolisis alkali. Produksi biogas dilakukan dengan menggunakan sistem fermentasi tipe batch secara anaerob.. Digester biogas berkapasitas $19 \mathrm{~L}$ dengan pra-perlakuan menghasilkan persentase $\mathrm{CH}_{4}$ paling tinggi yaitu $34,12 \%$, dibandingkan dengan tanpa pra-perlakuan $(29,77 \%)$. Total potensi energi yang dihasilkan pada produksi biogas dengan pra-perlakuan (94 kJ), dimana lebih besar 90,16\% dari tanpa pra-perlakuan $(49,43 \mathrm{~kJ})$.
\end{abstract}

Kata kunci: metan, eceng gondok, pra-perlakuan

\begin{abstract}
Biogas as one of the alternative energy fuels could be produced by using biomass raw material such as water hyacinth. That raw material has quite high of cellulose and hemicellulose content. In biogas production, it needs a low concentration of cellulose. The effective to breakdown polysaccharide bondage into its monomers is by using alkaline hydrolysis pre-treatment method. Therefore it used to be the water hyacinth alkali pretreatment. The biogas production was undergo in batch fermentation type, anaerobically. The $19 \mathrm{~L}$ anaerobic digester in pre-treated raw material showed the highest content of $\mathrm{CH} 4$ in the amount of $34,12 \%$, compare to unpretreated one $(29,77 \%)$ The total potential energy of pre-treated raw material biogas fermentation $(94 \mathrm{~kJ})$ was $90,16 \%$ higher than the unpretreated one $(49,43 \mathrm{~kJ})$.
\end{abstract}

Key words: methane, water hyacinth, pre-treatment

\section{PENDAHULUAN}

Penggunaan energi alternatif yang bersifat terbarukan mulai menjadi perhatian masyarakat. Biogas merupakan salah satu jenis energi terbarukan yang pengembangan proses dan teknologi pembuatannya masih terus diteliti, dimana salah satunya adalah 
pengembangan potensi biomassa sebagai bahan baku pembuatan biogas. Eceng gondok merupakan salah biomassa yang kelimpahannya cukup tinggi dan berpotensi menjadi cemaran bagi perairan air tawar terbuka.

Eceng gondok memiliki karakteristik komposisi yang didominasi oleh polisakarida berupa selulosa dan hemiselulosa (Tabel 1).

Tabel 1. Komposisi Eceng Gondok

\begin{tabular}{|c|c|c|}
\hline No. & Komponen & $\begin{array}{c}\text { Komposisi } \\
(\mathbf{\%})\end{array}$ \\
\hline $\mathbf{1}$ & Selulosa & 25 \\
\hline $\mathbf{2}$ & Hemiselulosa & 35 \\
\hline $\mathbf{3}$ & Lignin & 10 \\
\hline $\mathbf{4}$ & Abu & 20 \\
\hline $\mathbf{5}$ & Nitrogen & 3 \\
\hline
\end{tabular}

Sumber : Bhattacharya dan Kumar (2010)

Penggunaan eceng gondok sebagai bahan baku pembuatan biogas mulai diperhatikan potensi penggunaannya. Berdasarkan karaktersitik kimiawi eceng gondok di Tabel 1, potensi pembuatan biogas dari eceng gondok mengalami kendala karena struktur lignoselulosa yang sulit dikonversi menjadi bentuk senyawa lainnya oleh bakteri (Budiman, 2012). Oleh karena itu perlu adanya pra-perlakuan terhadap eceng gondok.

Pra-perlakuan merupakan tahap esensial dalam preparasi selulosa yang akan dihidrolisis secara enzimatik sehingga menghasilkan yield (berupa monosakarida) yang lebih tinggi. (Wyman dkk., 2005).

Hanjie (2010) menyebutkan bahwa proses pembentukan biogas meliputi empat tahapan yaitu : (a) Hidrolisis, pada tahap ini terjadi penguraian bahan-bahan organik mudah larut dan pencernaan bahan organik yang komplek menjadi sederhana, perubahan struktur bentuk polimer menjadi bentuk monomer; (b) Acidogenesis, pada tahap pengasaman komponen monomer (gula sederhana) yang terbentuk pada tahap hidrolisis akan menjadi bahan makanan bagi bakteri pembentuk asam. Produk akhir dari perombakan gula-gula sederhana ini yaitu asam propionat, format, laktat, alkohol, dan sedikit butirat, gas karbondioksida, hidrogen dan amonia ; (c) Acidogenesis, pada tahap ini asam asetat terbentuk dari hasil penggunaan senyawa hasil acidogenesis oleh mikroorganisme. Beberapa jenis gas turut dihasilkan, yakni hidrogen dan karbondioksida, (d) Metanogenesis, pada tahap ini terjadi proses pembentukan gas metana. Jumlah kandungan gas metana hasil fermentasi dipengaruhi dari tahapan-tahapan tersebut, salah satunya adalah hidrolisis. Pemberian pra-perlakuan pada eceng gondok di tahap hidrolisis akan mempengaruhi produksi biogas.

\section{METODOLOGI}

Metode pre-treatment secara kimiawi terdiri dari perlakuan menggunakan senyawa basa, asam, gas, agen oksidasi dan lain-lain (Kamm $d k k$., 2006 dalam Moler 2006). Menurut Millet (1976), pemberian pra-perlakuan alkali oleh $\mathrm{NaOH}$ pada kayu dengan jenis hardwood mampu menurunkan kandungan lignin dari 24\%-55\% menjadi $20 \%$.

Pra-perlakuan yang digunakan dalam penelitian ini adalah pra-perlakuan hidrolisis alkali yaitu dengan menambahkan larutan $\mathrm{NaOH}$ dengan konsentrasi $1 \%$. Metode praperlakuan dilakukan dengan menggunakan perendaman pada larutan senyawa alkali. Berdasarkan Patil et.al. (2011), penggunaan $\mathrm{NaOH} 1 \%$ untuk pra-perlakuan alkali pada eceng gondok yang difermentasi untuk produksi biogas, mampu menunjukkan kenaikan kandungan gas metan.

Eceng gondok yang digunakan sebanyak $5 \mathrm{~kg}$ dan dilakukan pra-perlakuan alkali dengan perendaman eceng gondok di dalam larutan $\mathrm{NaOH} 1 \%$ pada suhu $40-50^{\circ} \mathrm{C}$ selama 2 hari. Setelah pra-perlakuan tersebut dilakukan, $\mathrm{pH}$ eceng gondok dikondisiskan pada $\mathrm{pH} 7$ (netral).

Pencampuran bahan baku dilakukan dengan menambahkan kotoran sapi. Adapun perbandingannya adalah 4:1 (berat basah) dengan komposisi bahan $80 \%$ eceng gondok dan $20 \%$ sludge kotoran sapi. Sesuai dengan kapasitas digester yang digunakan, yaitu 15 liter, maka eceng gondok yang digunakan sebanyak 12 liter dan sludge kotoran sapi sebanyak 3 liter [?].

Proses produksi biogas optimal, perlu dilakukan pada kondisi kerjanya. Bahan campuran tersebut dimasukan ke dalam digester, kemudian digester dikondisikan pada suhu lingkungan sekitar $23-27^{\circ} \mathrm{C}$ dengan tanpa pengadukan pada bahan. Selanjutnya 
dilakukan pengambilan data berupa volume gas dalam slang waktu 2 hari selama 22 hari.

\section{HASIL DAN PEMBAHASAN}

Hasil analisa kandungan senyawa organik dari eceng gondok dan sludge kotoran sapi yang digunakan sebagai bahan baku ditunjukan pada Tabel 2 dan Tabel 3.

Tabel 2. Karakteristik Eceng Gondok

\begin{tabular}{|c|c|c|}
\hline Jenis Analisa & Satuan & Hasil Analisa \\
\hline C-Organik & $\% \mathrm{BK}$ & 25,04 \\
\hline NTK & $\% \mathrm{BK}$ & 0,18 \\
\hline $\mathrm{Ph}$ & - & 7,75 \\
\hline Kadar Air & $\% \mathrm{BB}$ & 85,27 \\
\hline Berat Jenis & $\mathrm{gr} / \mathrm{cm} 3$ & 0,47 \\
\hline
\end{tabular}

(Sumber : Analisa Kimia Lab. B3 Teknik Lingkungan ITB)

Tabel 3. Karakteristik Sludge Kotoran Sapi

\begin{tabular}{|c|c|c|}
\hline Jenis Analisa & Satuan & Hasil Analisa \\
\hline C-Organik & $\% \mathrm{BK}$ & 38,82 \\
\hline NTK & $\% \mathrm{BK}$ & 1,61 \\
\hline $\mathrm{pH}$ & - & 7,75 \\
\hline Kadar Air & $\% \mathrm{BB}$ & 92,09 \\
\hline Berat Jenis & $\mathrm{gr} / \mathrm{cm} 3$ & 1,03 \\
\hline
\end{tabular}

Pada saat kedua bahan tersebut dicampurkan maka komposisi campuran akan memiliki karakteristik yang berbeda. Campuran bahan memiliki pH 7,75 karena masing-masing bahan mempunyai $\mathrm{pH} 7,75$. $\mathrm{pH}$ yang optimum untuk bakteri pembentuk metan berada di kisaran 6,6-7,5 (Yunus,1995). Kadar air dari campuran bahan tersebut adalah sebesar $92,08 \%$, dimana nilai ini cukup ideal untuk pembuatan biogas yang memiliki kadar air optimum sebesar 90\% (Fairus, 2011). Rasio $\mathrm{C} / \mathrm{N}$ dari bahan campuran itu memiliki nilai sebesar 35,67. Nilai ini terlalu besar, dimana nilai rasio $\mathrm{C} / \mathrm{N}$ yang optimum untuk proses anaerob adalah 25-30 (Simamora, 2006).

\section{Perbandingan Produksi Gas Antara Tanpa Dan Dengan Pra-Perlakuan}

Dari Gambar 1 dapat dilihat bahwa produksi biogas yang mengalami pra-perlakuan lebih banyak dibandingkan dengan digester kontrol (tanpa pra-perlakuan). Digester pra-perlakuan memiliki nilai maksimum produksi biogas sebesar $1.98 \mathrm{~L}$ dan nilai minimumnya sebesar 1.6 L. Digester kontrol memiliki nilai maksimum produksi biogas sebesar $1.5 \mathrm{~L}$ dan nilai minimum sebesar $1.2 \mathrm{~L}$. Hasil produksi biogas dengan pra-perlakuan tersebut masih lebih baik dibandingkan dengan hasil tanpa pra-perlakuan yang hanya mempunyai nilai maksimum produksi biogas sebesar $1.416 \mathrm{~mL}$ pada hari ke-6.

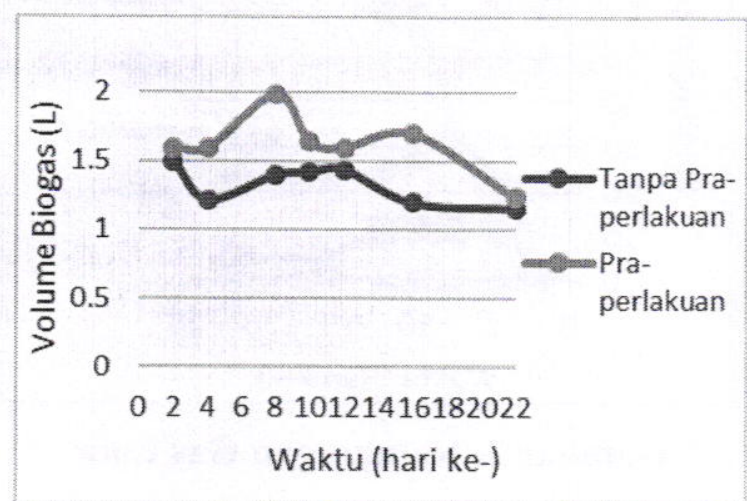

Gambar 1. Kurva Volume Gas terhadap Waktu
untuk Tanpa dan Dengan Pra-perlakuan

\section{Perbandingan Produksi $\mathrm{CH}_{4}$ Antara Tanpa Dan Dengan Pra-Pelakuan}

Dari Gambar 2 ditunjukkan bahwa nilai persen gas metan yang dihasilkan oleh digester praperlakuan sebesar $34,1 \%$ dan digester kontrol sebesar 29,7\%. Nilai minimum kandungan $\mathrm{CH}_{4}$ dari masing-masing digester dicapai pada hari yang sama yaitu hari ke-2 dengan kandungan $\mathrm{CH}_{4}$ digester pra-perlakuan dan kontrol masing-masing sebesar $3,9 \%$ dan $2,4 \%$. Hal tersebut disebabkan karena bakteri pembentuk metan yang belum banyak terbentuk atau belum aktif.

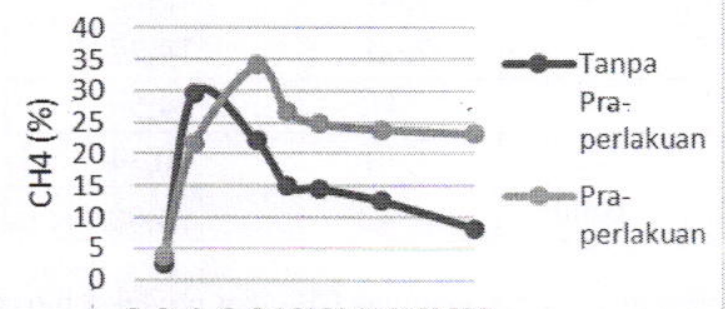

0246810121416182022

Waktu (hari ke-)

Gambar 2. Kurva Produksi $\mathrm{CH}_{4}$ terhadap Waktu untuk Tanpa dan Dengan Pra-perlakuan

Dari Gambar 3 terlihat bahwa gas yang mendominasi dari kandungan gas keseluruhan adalah $\mathrm{N}_{2}$. Pada mekanisme reaksi dekomposisi 
anaerobik gas $\mathrm{CH}_{4}$ yang terbentuk harus 1:1 dengan gas $\mathrm{CO}_{2}$ namun pada praktiknya gas $\mathrm{CH}_{4}$ dan $\mathrm{CO}_{2}$ yang dihasilkan mempunyai selisih yang jauh.

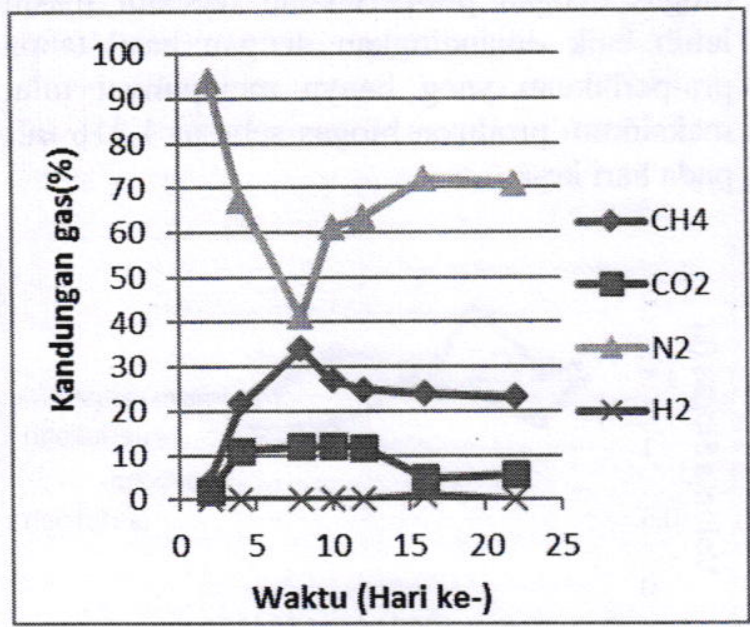

Gambar 3. Kandungan Gas Lain

Hal tersebut dapat diakibatkan oleh sedikitnya kelompok bakteri hidrolitik dan bakteri asetogen yang dapat menghasilkan $\mathrm{CO}_{2}$. Selain itu juga dapat diakibatkan oleh kondisi proses yang kurang sesuai, seperti temperature fermentasi, kondisi digester yang tidak sepenuhnya kedap udara, dan kurangnya nutrien yang dibutuhkan oleh bakteri. Kandungan gas lainnya yaitu Hidrogen, hanyak terdeteksi pada hari ke-16 dengan nilai dibawah $1 \%$.

Tabel 4. Potensi Energi Biogas pada Digester Tanpa-Perlakuan dan Perlakuan

\begin{tabular}{|c|c|c|}
\hline Hari ke- & $\begin{array}{c}\text { Kontrol } \\
(\mathbf{k J})\end{array}$ & $\begin{array}{c}\text { Pra-perlakuan } \\
(\mathbf{k J})\end{array}$ \\
\hline 2 & 1,30 & 2,24 \\
\hline 4 & 13,03 & 12,50 \\
\hline 8 & 11,13 & 24,24 \\
\hline 10 & 7,66 & 15,82 \\
\hline 12 & 7,50 & 14,27 \\
\hline 16 & 5,41 & 14,59 \\
\hline 22 & 3,40 & 10,34 \\
\hline Total & 49,43 & 94,00 \\
\hline
\end{tabular}

Besarnya kandungan gas $\mathrm{CH}_{4}$ dan produksi biogas berbanding lurus dengan nilai kalor dan potensi energi yang diperoleh. Semakin besar kandungan gas $\mathrm{CH}_{4}$ dan produksi biogas maka semakin besar nilai kalor dan potensi energi yang dihasilkan. Pada digester pra-perlakuan, nilai kalor dan energi biogas tertinggi dicapai saat gas metan mencapai komposisi tertinggi dan volume maksimum, yaitu pada hari ke-8 dengan nilai kalor mencapai 12,24
$\mathrm{kJ} /$ liter, dengan nilai energi biogas $24,24 \mathrm{~kJ}$. Total potensi energi biogas hasil pra-perlakuan mencapai $94 \mathrm{~kJ}$, dibandingkan biogas tanpa pra-perlakuan yang hanya menghasilkan $49,93 \mathrm{~kJ}$.

\section{KESIMPULAN}

1. Produksi biogas dari eceng gondok yang mengalami pra-perlakuan secara hidrolisis alkali menunjukan produktivitas $41,4 \%$ lebih besar dibandingkan dengan produksi biogas tanpa pra-perlakuan, dapat dilihat bahwa nilai optimum dari produksi biogas digester praperlakuan sebesar $1.980 \mathrm{~mL}$ pada hari ke- 8 sedangkan untuk digester tanpa pra-perlakuan adalah $1.400 \mathrm{~mL}$.

2. Kandungan gas $\mathrm{CH}_{4}$ yang dihasilkan oleh digester pra-perlakuan mempunyai nilai optimum yang lebih besar yaitu $34,12 \%$ pada hari ke-8, sedangkan untuk digester kontrol nilai optimum yang diperoleh hanya $29,77 \%$ pada hari ke-4.

3. Nilai kalor dan energi biogas tertinggi dicapai saat gas metan mencapai komposisi tertinggi dan volume maksimum, yaitu pada hari ke- 8 dengan nilai kalor mencapai $12,24 \mathrm{~kJ} /$ liter, dengan nilai energi biogas $24,24 \mathrm{~kJ}$.

\section{DAFTAR PUSTAKA}

Abdillah, Jaka dkk. 2011. Natrium Hidroksida (Naoh) Sebagai Hidrolisa Basa Dalam Pra-perlakuan Produksi Biogas Dengan Bahan Baku Eceng Gondok (Eichornia Crassipes), Teknik Kimia, Fakultas Teknik Industri, Institut Teknologi Sepuluh November, Surabaya.

Chanakya, H.N., S. Borgaonkar, G. Meena dan K.S. Jagadish. 1993. Solid

Phase Biogas Production with Garbage or Water Hyacinth. Bioresource Technology Vol. 46 Hal. 227- 231, Elsevier Ltd.

Bhattacharya, Anjanabha dan Pawan Kumar. 2010. Water Hyacinth As A Potential Biofuel Crop. USA: National Environmental Sound Production Agriculture Laboratory.

Budiman. 2012. Bioetanol dari Eceng Gondok, (online), (http://www.sobatbumi.com/s olusi/view/155, diakses tanggal 1 November 2012).

Fairus, Sirin dkk. 2011. Pemanfaatan Sampah 
Organik Secara Padu, Teknik Kimia, Fakultas Teknologi Industri, Institut Teknologi Nasional, Bandung.

Hanjie, Zhang. 2010 .Sludge Treatment To Increase Biogas Production.TritaLWR Degree Project 10-20. Sweden

Millet M A, Baker AJ, Satter L D. (1976). Physical And Chemical Pretreatments For Enhancing Cellulose Saccharification. Biotech Bioeng Symp. 6, 125-153
Simamora, S., Salundik, Sri. W., Surajudin. 2006. Membuat Biogas. Agro Media Pustaka, Jakarta

Wyman, C.E., E.D.Bruce, R.T.Elander, M. Holtzapple, Michael R.L. Y,Y.Lee. (2005) : Coordinated development of leading biomass pretreatment technologies. J.Biosource Technology

Yunus, M., 1995. Teknik Membuat Dan Memanfaatkan Unit Gas Bio, Universitas Gajah Mada Press, Yogyakarta. 